\title{
Orta Karadeniz Bölgesinde Kırsal Alanlar İçin Keten Bir Şans Mı? Kârlılık Analizi ve Yapılabilirliği
}

Is Flax a Chance for Rural Areas in the Middle Black Sea Region? Profitability Analysis and Feasibility

\author{
Esin HAZNECİ ${ }^{* *}$, Şahane Funda ARSLANOĞLU²
}

\section{$\ddot{\mathbf{O} z}$}

Bu çalışma liflik keten yetiştiriciliğinin Orta Karadeniz Bölgesinde kârlı bir üretim faaliyeti olarak yapılabilirliğini ve kışlık buğdaya alternatif bir ürün olup olamayacağını ortaya koymak amacıyla yapılmıştır. Araştırmanın ana materyalini 2019-2020 üretim döneminde Sinop ve Samsun illerinde 3 farklı lokasyonda yapılan deneme alanlarında çiftçi koşullarında yetiştirilen liflik keten üretim verileri oluşturmuştur. Samsun ili Bafra ilçesi Elifli köyü, Sinop ili Merkez ilçe Taşmanlı köyü ve Sinop ili Ayancık ilçesi Söküçayırı köyü lokasyonları için keten üretim maliyetleri ve karlılığı ayrı ayrı hesaplanmış, daha sonra Samsun ve Sinop illeri ortalama buğday üretim maliyeti ile karşılaştırılmıştır. Araştırmada incelenen lokasyonların tamamında masraflar içerisinde en büyük payı değişken masrafların oluşturduğu saptanmıştır. Sinop ili Ayancık ilçesi Söküçayırı köyünde toplam masrafların yaklaşık \%89'u, Sinop ili Merkez ilçe Taşmanlı köyünde \%83'ü ve Samsun ili Bafra ilçesi Elifli köyünde \%81’i değişken masraflardan oluşmaktadır. Sinop ili Merkez ilçe Taşmanlı köyü ve Samsun ili Bafra ilçesi Elifli köyü lokasyonlarında keten üretim faaliyetinde bulunan işletmeler üretim masraflarının tamamını karşılayabiliyorken, Sinop ili Ayancık ilçesi Söküçayırı köyü lokasyonunda faaliyet gösteren işletmelerin üretimin değişken masraflarını dahi karşılayamadıkları gözlenmiştir. Araştırma sonucunda, kısmen veya tamamen mekanizasyonla yapılan liflik keten üretiminin bölgede yetiştirilen buğdaya göre daha kârlı olduğu tespit edilmiştir. İşletmeler tüm masraflarını karşıladıktan sonra Sinop ili Merkez ilçe Taşmanlı köyünde 715.3 TL da ${ }^{-1}$, Samsun ili Bafra ilçesi Elifli köyünde $533.2 \mathrm{TL} \mathrm{da}^{-1}$ net kâr elde etmişlerdir. Tamamen el işçiliği ile üretilen keten lifinden ise zarar edildiği saptanmıştır. Araştırma sonucunda, liflik keten yetiştiriciliğinde yüksek verim ve kârlılık için tüm işlemlerin mekanizasyonla yapılmasının yanı sıra, bakım ve kültürel işlemlere gerekli özenin gösterilmesi önerilmektedir.

Anahtar Kelimeler: Liflik keten, Buğday, Üretim maliyetleri, Kârlılık analizi, Sinop, Samsun, Türkiye

\footnotetext{
1*Sorumlu Yazar/Corresponding Author: Esin HAZNECİ, Ondokuz Mayıs Üniversitesi, Ziraat Fakültesi, Tarım Ekonomisi Bölümü, 55139, Atakum/Samsun, Türkiye. E-mail: esin.hazneci@omu.edu.tr (D) OrcID: 0000-0002-8695-028X

2 Şahane Funda Arslanoğlu, Ondokuz Mayıs Üniversitesi, Ziraat Fakültesi, Tarla Bitkileri Bölümü, 55139, Atakum/Samsun, Türkiye. E-mail: farslanoglu@omu.edu.tr (D) OrcID:0000-0001-5773-2665.

Atıf/Citation: Hazneci E., Arslanaoğlu Ş. F. Orta Karadeniz Bölgesinde Kırsal Alanlar İçin Keten Bir Şans Mı? Kârlılık Analizi ve Yapılabilirliği. Tekirdă̆ Ziraat Fakültesi Dergisi, 18 (3), 586-598.

(CBu çalışma Tekirdağ Namık Kemal Üniversitesi tarafından Creative Commons Lisansı (https://creativecommons.org/licenses/by-nc/4.0/) kapsamında yayınlanmıştır. Tekirdağ 2021
} 


\begin{abstract}
This study was carried out to reveal the feasibility of fiber flax cultivation as a profitable production activity in the Middle Black Sea Region and whether it can be an alternative product to winter wheat. The main materials of the research were the production data of fiber flax grown under farmer conditions in the trial areas in 3 locations in Sinop and Samsun provinces during the 2019-2020 production period. Flax production costs and profitability were calculated separately for the locations of Elifli village in Bafra district of Samsun province, Taşmanlı village of Sinop province central district and Söküçayırı village of Sinop province Ayancık district, and then compared with the average wheat production cost of Samsun and Sinop provinces. It was determined that variable costs constitute the largest share of the costs in all of the locations examined in the study. Approximately $89 \%$ of the total expenses in Söküçayırı village in Ayancık district of Sinop province, $83 \%$ in Taşmanlı village in the central district of Sinop province and $81 \%$ in Elifli village of Bafra district in Samsun province consist of variable expenses. It was also observed that the enterprises in Sinop province central district Taşmanlı village and Samsun province Bafra district Elifli village could cover all the production costs, while the enterprises in Söküçayırı village of Ayancık district in Sinop province cannot cover even the variable costs of production. As a result of the research, it was determined that fiber flax production, which is partially or entirely mechanized, is more profitable than the wheat grown in the region. After covering all their expenses, the enterprises made a net profit of $715.3 \mathrm{TL} \mathrm{da}^{-1}$ in the Taşmanl village of central district in Sinop province and $533.2 \mathrm{TL} \mathrm{da}^{-1}$ in the Elifli village of Bafra district in Samsun. It was determined that farmers growing flax fiber by hand made a loss. Therefore, it was suggested that all processes should be done with mechanization for high efficiency, and profitability in fiber flax cultivation, as well as cultural practices should be paid attention.
\end{abstract}

Key Words: Fiber flax, Wheat, Production costs, Profitability analysis, Sinop, Samsun, Turkey 


\section{Giriş}

Keten bitkisinin, marjinal alanlardan birinci sınıf tarım arazilerine kadar birçok iklim bölgesinde yazlık veya kışlık olarak tarımı yapılabilmektedir. Lif ve tohumlarından yararlanılan ketenin anavatanı Akdeniz havzasıdır. Lifleri ev tekstili, perde, yazlık kıyafetler gibi alanlarda hammadde sağlamanın yanı sıra, tekstilde kullanılamayan lif artıkları değerli kağıt yapımında kullanılmaktadır. Kuruma özelliğine sahip olan tohum yağı, yağlı boya sanayisinin temel hammaddesidir. Yağı alındıktan sonra kalan küspesi gıda takviye edici ürün ve yem amaçlı değerlendirilmektedir (Shuster, 1992). Keten, pamuktan sonra dünyada kullanımı en fazla olan bitkisel lif kaynağ 1 olmasına rağmen, pamuğun ve sentetik lif kaynaklarının kullanım oranının artmasıyla ekim alanı tüm dünyada hızla azalmıştır. Buna rağmen doğal liflere olan ilgi nedeniyle keten üretimi ve keten kumaşı kullanımı varlığını az ya da çok sürdürmüştür (Kiryluk ve Kostecka, 2020). Türkiye'de en fazla üretimi yapılan lif bitkisi pamuktur, ancak pamuk lifi üretimi toplam tüketimi karşılayamamaktadır. Tekstil sektörünün ihtiyaç duyduğu hammaddenin yarıya yakını ithalatla karşılanmaktadır (Aytaç ve ark., 2020). Pamuğun yetiştirilme olanağının bulunmadığı iklim koşullarında ve alanlarda yetiştirilebilecek en önemli lif bitkilerinden birisi ketendir.

Karadeniz Bölgesi sahil kuşağı ve iç geçit bölgelerinde kışlık olarak ekilebilmesi ve münavebe alanlarında da değerlendirilebilmesi bakımından önem arz eden keten bitkisi; uzun, kaliteli ve dayanıklı lifi ile tekstil sanayi için alternatif bir kaynak olma potansiyeline sahiptir (Yılmaz ve Uzun, 2019). Türkiye, dünyada keteni lif amaçl1, kışlık yetiştirebilen nadir ülkelerden biridir. Karadeniz Bölgesi’nde Samsun'dan Şile'ye kadar olan sahil kesimi ile Ege bölgesinde bazı il ve ilçelerde (İzmir-Ödemiş-Tire) kışlık ekilmektedir. Buna rağmen son 20 yıldır gerek keten lifi, gerek tohum ve diğer ürünleri olmak üzere tüm keten mamullerini ithalatla karşılanmakta, farklı 28 üründe keten ve ürünleri ithalatı yapılmaktadır. Lif ihtiyacının \%73.3'ünü Avrupa Birliği (AB) üyesi ülkelerden, diğer kısmı Çin'den karşılamaktadır. Bu amaçla, 2019 yılında keten lifi/iplik için yaklaşık 35 milyon dolar, tohum için 8 milyon dolar döviz harcanmıştır (Aytaç ve ark., 2020).

Keten ekimi 1964 yılından sonra hızla azalmaya başlamıştır. Sentetik liflerin daha ucuz olması, işlenebilirliğinin kolaylığı, istenilen zamanda ve miktarda elde edilebilir olmaları nedeniyle; keten, kenevir gibi üretimi işçilik gerektiren liflerin kullanımı azalmıştır. Bununla birlikte doğal liflerde kalitenin çevre koşulları ve işleme yöntemlerine göre değişkenlik göstermesi, standart kalitede liflere ulaşmayı zorlaştırmıştır. Ayrıca keten ve kenevire alternatif olabilecek buğday, mısır, şeker pancarı gibi tarım ürünlerinin üretiminin büyük oranda mekanizasyona dayalı olması, keten ve kenevirde işçilik maliyetlerinin yüksekliği, bu bitkilerin kıtık ve kısa liflerini kullanan kağıt fabrikalarının kapatılması da keten tarımının azalmasına neden olmuştur. Fakat keten lifinin kullanım alanındaki yarayışlılığı, lifinin esnekliği, parlaklığı, dayanıklılığı nedeniyle yazlık kumaşlar ve ev tekstilinde önemli bir kaynak olması, Fransa, Belçika, Rusya gibi ülkelerde üretiminin devam etmesine neden olmuştur.

Keten bitkisi etkili kök derinliği 10 cm olan zayıf kök yapısı ile topraktan buğday, arpa gibi bitkilere göre daha az besin maddesi kaldırmaktadır. Dünyada kışlık olarak nadir ekilen ülkelerden birisi Türkiye'dir (Turan, 2000). Herhangi bir hastalık ve zararlıya karşı kışlık ekimlerde pestisit kullanımı yok ya da azdır. Türkiye'de keten tarımının artmamasının en önemli nedeni, hasat- harman mekanizasyonunun olmaması ve liflerin ipe ve tekstile dönüştürülmesi aşamalarında gerekli teknolojinin eksikliğidir. $\mathrm{Bu}$ durum günümüzde ketene dayalı tekstil ürünlerinin ve keten ipliğinin ithalatını zorunlu hale getirmiştir.

Konu ile ilgili literatür incelendiğinde, keten üretim yöntemi ve pazarlaması ile ilgili çalışmaların daha çok yurt dişında yapıldığı dikkati çekmektedir (Heller ve ark., 2014; Foulk ve ark., 2011; Bourmaud ve ark., 2010; Smeder ve Liljedahl S., 1996; Foulk, 2002; Akin, 2000; Robinson, 1936; Howard, 1941; Powers, 1936; Rada ve DeLoach, 1942). Bu konu ile ilgili yurt içinde yapılmış çalışma sayısı oldukça sınırlıdır (Arslan ve ark., 2011, Arslanoğlu ve ark., 2017). Keten maliyeti ve ekonomik yönü ile ilgili çalışmalar araştırıldığında doğrudan liflik ketenin maliyeti ile ilgili olarak yalnızca Kuhlman ve Robinson'ın 1938 yılında yaptıkları çalışmaya rastlanmıştır. Son yıllarda konu ile ilgili diğer çalışmalar daha çok kompozitler için yeni düşük maliyetli keten lifi üretimi ve optimizasyonu (Hosseinzadeh ve ark., 2020; Li ve ark., 2020, Megahed ve ark., 2020, Deng ve ark., 2019, Savran ve Aydın, 2018) ve liflerin çeşitli uygulamalar için uygun maliyetli işlenmesi ve atıklarının geri dönüştürülebilmesi ile ilgili olduğu görülmektedir (Xu ve ark., 2017; Kaur ve ark., 2016). 
Türkiye'de son yıllarda neredeyse hiç üretimi olmayan liflik keten üretiminin, özellikle keten yetiştiriciliği için uygun ekolojiye sahip Orta Karadeniz Bölgesi'nde faaliyette bulunan üreticiler için gelir getirici bir firsat olup olmayacağı konusunun araştırılması büyük önem arz etmektedir. Bu nedenle araştırmada, literatürde ülkemizde daha önce hiç çalışılmamış olan liflik keten üretiminin maliyetlerine ve kârllık analizine odaklanılmış, bu araştırma ile lif amaçlı keten üretiminin, yetiştirilen mevcut ürün karşısında kârllık durumunun belirlenmesi amaçlanmıştır. Türkiye'de tarım sektörünün en önemli ve güncel sorunları arasında yüksek ürün maliyetleri, küçük ve parçalı işletme yapısı ve tarım işletmelerinin büyük çoğunluğunda muhasebe kayıtlarının tutulmaması görülmektedir. Muhasebe kayıtlarının tutulmaması nedeniyle işletmelerde maliyetlerin ve gelirlerin tespitinde çoğunlukla anket yoluyla toplanan veriler kullanılmaktadır. Bu verilerin doğru elde edilmesi ve analizi ise uygulanacak politikaların uygun tespit edilmesine ve sahadan veri toplayan teknik elemanların niteliklerine bağlı olmaktadır (Keskin ve ark., 2014). Bu araştırmanın deneme alanlarında yürütülmüş olması ve üreticilerin uygulamalarının bizzat gözlenmesi nedeniyle, verilerin doğruluğu ve güvenilirliği bakımından da çalışma önemli görülmektedir.

Dünya genelinde 240293 hektar alanda liflik keten üretimi gerçekleştirilmekte ve bu alanda 868373 ton keten lifi üretilmektedir (Şekil 1). Toplam üretimin \%97'si Avrupa ülkelerinde gerçekleştirilirken, üretimin geri kalanı Afrika, Amerika ve Asya’da yapılmaktadır (SSekil 2) (Anonim, 2020a).

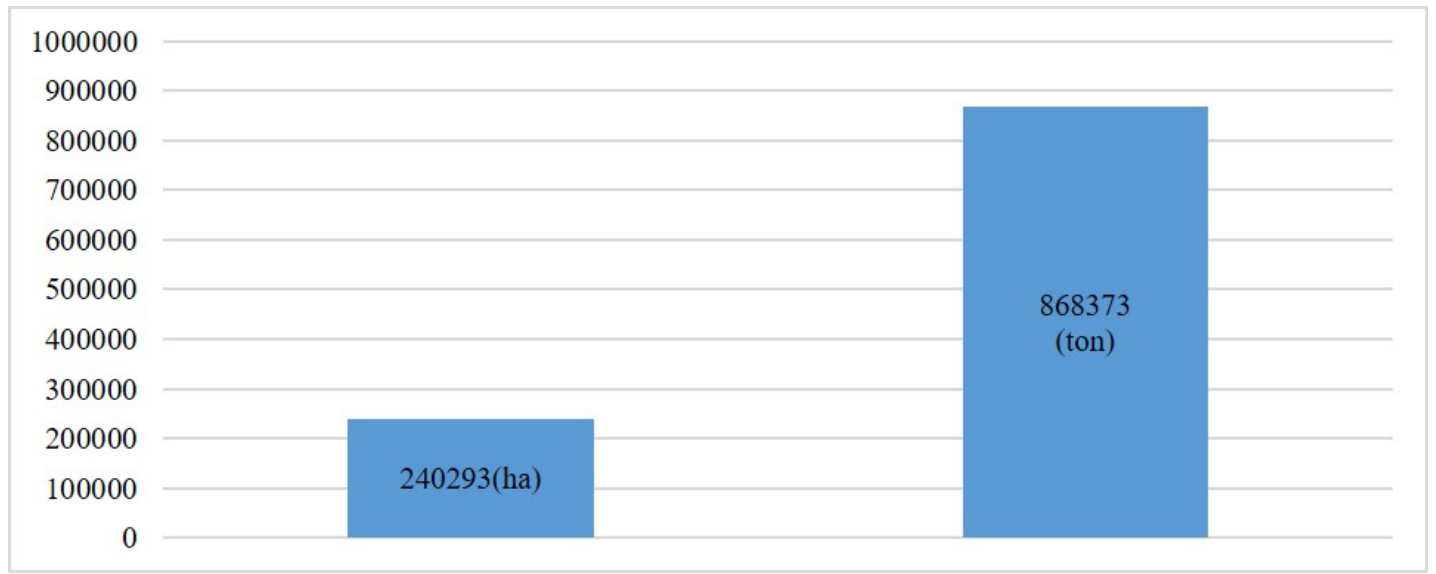

Figure 1. Production/yield quantities of flax fibre and tow in World (Total), 2018

Şekil 1. Dünya toplam keten lifi ve kıtık üretim alanı/verim miktarları, 2018

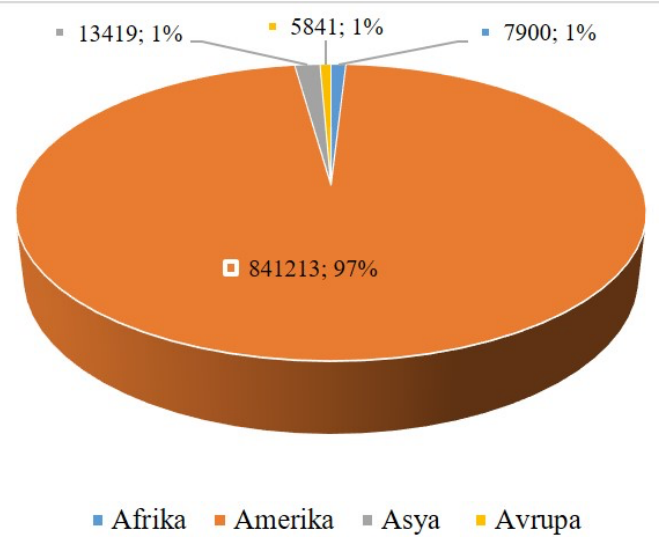

Figure 2. Production share of flax fibre and tow by region, 2018

Şekil 2. Kıtalara göre keten lifi ve lif üretim payı, 2018

Ortalama üretim miktarları 1994-2018 yılları dikkate alındığında, dünya keten lifi üretiminde ilk sırayı yaklaşık 444732 ton ile Fransa, ikinci sırada 219885 tonla Çin ve üçüncü sırada 45211 ton ile Rusya Federasyonu yer almaktadır. Keten lifi üretiminde bu ülkeleri sırasıyla Belarus, Belçika, Hollanda, Birleşik Krallık, BelçikaLüksemburg, Mısır ve İspanya izlemektedir (Şekil 3) (Anonim, 2020a). Şekil 3'de görüldüğü üzere Türkiye bu 

sıralama içerisinde bulunmamaktadır. Tablo l'de Türkiye'de 1988-2019 yılları arasında tekstil sektöründe kullanılmak amacıyla üretilen liflik keten üretim verileri görülmektedir.

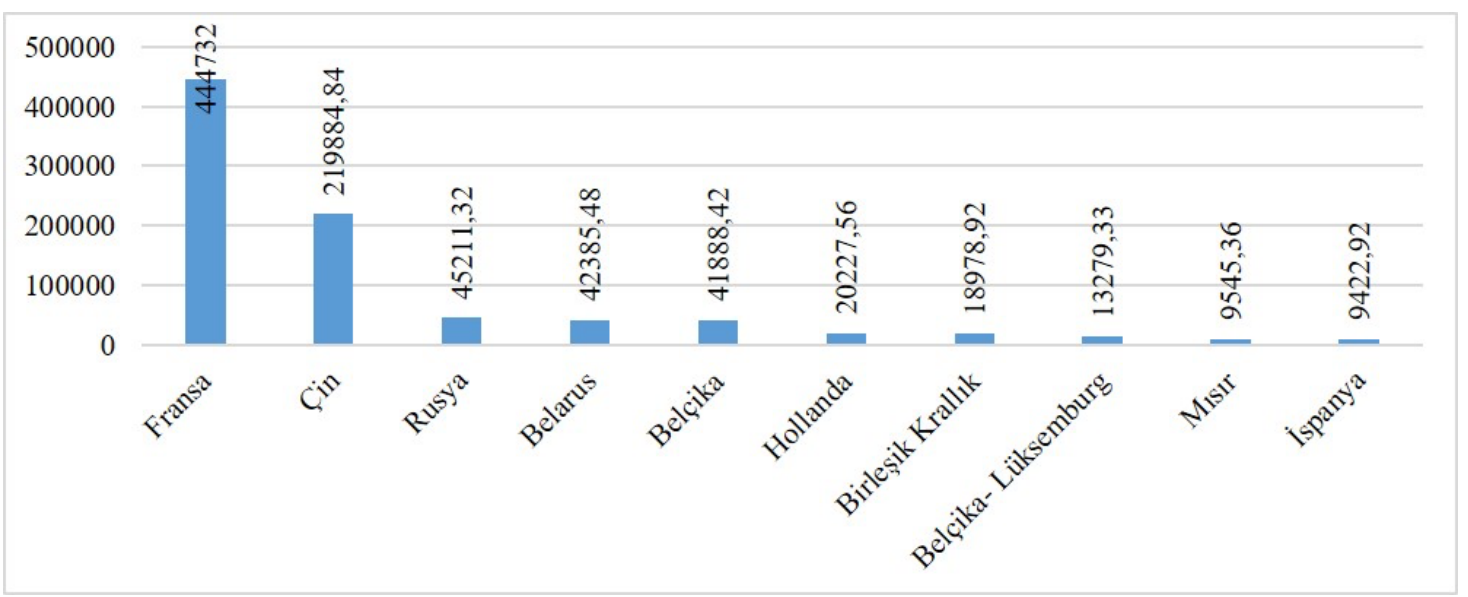

Figure 3. Production of flax fibre and tow: top 10 producers average 1994-2018 (tonnes) Şekil 3. Keten lifi ve kıtık üretiminde ilk 10 ülkenin üretim ortalaması 1994-2018 (ton)

Tablo 1. Liflik keten üretim verileri 1988-2019, Türkiye

Table 1. Fiber flax production data 1988-2019, Turkey

\begin{tabular}{|c|c|c|c|}
\hline & Ekilen alan (da) & Üretim (ton) & Verim $\left(\mathrm{kg} \mathrm{da}^{-1}\right)$ \\
\hline 1988 & 49.000 & 600 & 12 \\
\hline 1989 & 43.400 & 408 & 9 \\
\hline 1990 & 28.000 & 101 & 4 \\
\hline 1991 & 21.440 & 44 & 2 \\
\hline 1992 & 11.760 & 45 & 4 \\
\hline 1993 & 7.450 & 45 & 6 \\
\hline 1994 & 13.350 & 35 & 3 \\
\hline 1995 & 6.500 & 42 & 6 \\
\hline 1996 & 3.550 & 17 & 5 \\
\hline 1997 & 3.550 & 20 & 6 \\
\hline 1998 & 3.200 & 16 & 5 \\
\hline 1999 & 3.850 & 10 & 3 \\
\hline 2000 & 3.200 & 7 & 2 \\
\hline 2001 & 2.900 & 17 & 6 \\
\hline 2002 & 2.500 & 50 & 20 \\
\hline 2003 & 2.500 & 55 & 22 \\
\hline 2004 & 2.200 & 55 & 25 \\
\hline 2005 & 1.760 & 6 & 3 \\
\hline 2006 & 1.460 & 8 & 5 \\
\hline 2007 & 806 & 6 & 7 \\
\hline 2008 & 670 & 1 & 1 \\
\hline 2009 & 20 & 1 & 50 \\
\hline 2010 & 100 & 3 & 30 \\
\hline 2011 & 82 & 4 & 49 \\
\hline 2012 & 0 & 0 & - \\
\hline 2013 & 0 & 0 & - \\
\hline 2014 & 0 & 0 & - \\
\hline 2015 & 15 & 0.6 & 40 \\
\hline 2016 & 25 & 1 & 40 \\
\hline 2017 & 50 & 2 & 40 \\
\hline 2018 & 50 & 3 & 60 \\
\hline 2019 & 25 & 2 & 80 \\
\hline
\end{tabular}


Tablo I' göre, 1990'lı yıllara kadar oldukça geniş alanlarda üretilirken, bu yıllardan sonra hızla azalmış, hatta bazı yıllarda tohum ya da lif amaçlı hiç ekim yapılmamıştır. Günümüze gelindiğinde ise, 25 dekar gibi yok denecek kadar az bir alanda ekimi yapılmış ve dekarda $80 \mathrm{~kg}$ keten lifi üretimi gerçekleşmiştir (Anonim, 2020b).

Türkiye, liflik ve yağlık amaçla keten yetiştirmeye uygun ekolojiye sahip olmasına rağmen, Türkiye İstatistik Kurumu (TÜiK) verilerine göre, 2004 yllından beri liflik, 2012 yılından bu yana yağlık keten ekilişi neredeyse yapılmamaktadır. Türkiye'de her aşaması tamamen el işçiliğine dayalı olan keten tarımı, iş̧̧ilik maliyetlerinin yüksekliği ve ekimden- iplik elde etmeye kadar tüm üretim aşamalarının insan gücüne dayalı olması nedeniyle tarımsal üretim içerisinde yerini koruyamadığı dikkati çekmektedir (Arslanoğlu ve ark., 2017). Son yıllarda ketenin yeniden üretime kazandırılmasıyla ilgili başlatılan çalışmalarla liflik keten ekilişi 2015 yılında 15 dekarla başlayıp, ancak 115 dekara kadar yükselmiş (Aytaç ve ark, 2020), hasat ve lif sıyırma, ipe dönüştürme aşamalarında geleneksel yöntemlerin dışına çıkılamaması ve mekanizasyonun yetersizliği nedeniyle istenen hızda artış sağlanamamıştır.

Günümüzde, dünya tekstil sanayisinin pamuk dışı lif kaynaklarına ihtiyaç duyması, bunları harmanlayarak yeni-alternatif dokumalar üretmek istemesi nedeniyle (Shuvo, 2020) iç ve dış piyasada tekstil sanayisinin talep ettiği ve bugün tamamını ithal ettiğimiz homojen kalitede keten lifi ihtiyacı her geçen gün artmaktadır (Anonim, 2000). Dünya toplam tekstil ihracatında 8.2 milyar dolarlık ihracat ve \%3'lük pazar payı ile 7 . sırada yer alan Türkiye için bu konu oldukça önem arz etmektedir (Anonim, 2018). Bu nedenle çalışmanın temel amacı, liflik keten yetiştiriciliğinin Orta Karadeniz Bölgesinde kârlı bir üretim faaliyeti olarak yapılabilirliği ve bölgede yaygın olarak yetiştirilen kışlık buğdaya alternatif bir ürün olup olamayacağını araştırmaktır.

\section{Materyal ve Metot}

\subsection{Deneme alanları ve yetiştirme koşullart}

Araştırmalar, 2019-2020 üretim döneminde Sinop ve Samsun illerinde yürütülmüştür. Ekimler, 20 Ekim 2019 tarihinde Sinop ili Ayancık ilçesi Söküçayırı Köyünde (41 51' 58.4136" Kuzey ve 34 30' 6.0300" Doğu) 12 dekar,

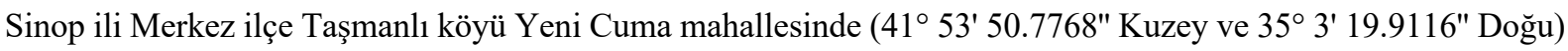
4 dekar çiftçi arazinde ve 25 Ekim 2019 tarihinde Samsun ili Bafra ilçesi Elifli köyünde yer alan Yeşil Küre -

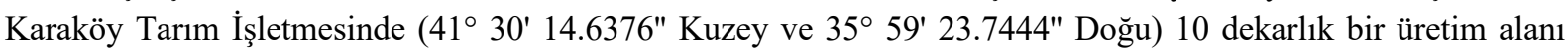
olmak üzere üç lokasyonda yapılmıştır.

Araştırma alanının haritası Şekil 4'de gösterilmiştir. Lokasyonlar Sinop Ayancık için lokasyon 1, Sinop Merkez için lokasyon 2, Samsun Bafra için lokasyon 3 olarak tanımlanmıştır. Ekimlerde, $6 \mathrm{~kg} / \mathrm{da}$ tohumluk hesabıyla Fransız orijinli liflik keten çeşidi Cristo Fiber kullanılmıştır. Ekimden önce Sinop'taki arazilerde 1 kez derin sürüm, ardından tırmıklama yapılmış, sonrasında elle serpme yöntemi ile ekim gerçekleştirilmiştir. Ekimle birlikte $5 \mathrm{~kg} / \mathrm{da}$ saf $\mathrm{N}$ hesabıyla 18-46-0 (N-P-K) formunda Diamonyum fosfat gübresi uygulanmış, ilkbaharda sapa kalkma döneminde $3 \mathrm{~kg} / \mathrm{da}$ saf $\mathrm{N}$ hesabıyla Üre formunda (\%46 azot) gübre uygulaması elle serpme yöntemiyle yapılmıştır. Sinop lokasyonlarında ön bitkinin buğday olduğu arazilerde ekim yapılmıştır.

Samsun'da yapılan üretimde ise önce pullukla derin sürüm, ardından kültivatör ile işleme ve buğday mibzeriyle tohum ekimi yapılmıştır. Ön bitkinin kenevir olduğu araziye, bir önceki yıl-kenevir üretimi için, kenevir ekiminden önce 3 ton/da hesabıyla olgunlaşmış tavuk gübresi uygulanmıştır. Kenevir hasatından hemen sonra arazi işlenerek herhangi bir gübre uygulanmaksızın keten ekimi yapılmıştır. İlkbaharda, bitkilerin sapa kalktığı dönemde $5 \mathrm{~kg} / \mathrm{da}$ saf $\mathrm{N}$ hesabıyla 13.5-0-45.5 $\left(\mathrm{NO}_{3}-0-\mathrm{K}_{2} \mathrm{O}\right)$ formüllü yaprak gübresi (CET $46+\mathrm{ME}$ ticari markalı) uygulanmıştır. 


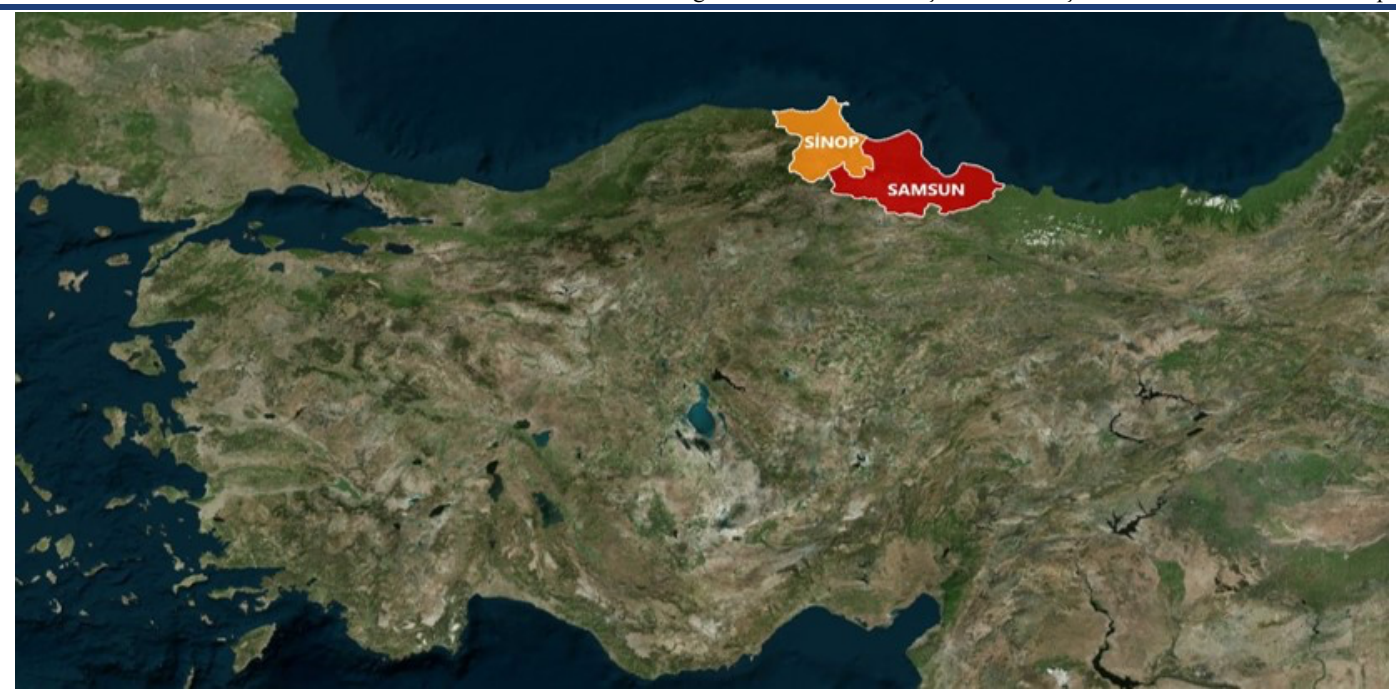

Figure 4. A survey of the research areas in Turkey, Sinop and Samsun provinces

Şekil 4. Türkiye'deki araştırma alanının haritası, Samsun ve Sinop illeri

Üretim alanlarında üretim süresince herbisit kullanılmamış, tarla alanı içerisinde görülen otlarla, bitkilerin sapa kalkma döneminde el işçiliği ile mücadele edilmiştir. Deneme alanlarında sulama yapılmamıştır. Hasatlar, yeşilsarı olum döneminde tüm lokasyonlarda Temmuz ayının ilk haftası tamamlanmıştır.

Denemelerin yürütüldüğü Samsun ve Sinop lokasyonlarının iklimi birbirine benzer olup, kış aylarının ılık geçtiği, ılıman Karadeniz iklimidir. Sinop Ayancık lokasyonunda (lokasyon 1) toprak killi yapıda, organik madde içeriği orta, fosfor bakımından yüksek, potas bakımından orta düzeyde, $\mathrm{pH}$ düzeyi 6.5 ve eğim \%6'dır. Sinop Merkez ilçe Taşmanlı lokasyonunda (lokasyon 2), killi, organik madde düzeyi orta, pH düzeyi 7, eğim \%4, potasyum ve fosforca orta düzeyde belirlenmiştir. Samsun Bafra lokasyonunda (lokasyon 3) ise toprak yine killi yapıda, organik madde seviyesi yüksek, fosforca zengin, potasça orta düzeyde, pH 6.5 ve eğim \%3 ölçülmüştür.

Samsun Bafra, Sinop Merkez Taşmanlı ve Sinop Ayancık lokasyonları için keten üretim maliyeti ayrı ayrı hesaplanmış, daha sonra Samsun ve Sinop illeri buğday ortalama üretim maliyeti ile karşılaştırılmıştır. Her lokasyonda farklı uygulamalar yapılmış olması nedeniyle hesaplamalar lokasyonlar için ayrı ayrı verilmiştir. Örneğin ekim ve hasat-toplama uygulamaları lokasyon 3'de mekanizasyon kullanılarak yapılırken, lokasyon 2'de ekim ve hasat el işçiliği ile yapılmıştır. Keten havuzlama, lif sıyırma ve istifleme işlemleri ise lokasyon 2 ve 3 'de mekanizasyonla gerçekleştirilirken, lokasyon 1'de geleneksel yöntemlerle elle yapılmıştır.

\subsection{Verilerin analiz metodu}

Çalışmada yalnızca keten yetiştiriciliğinin kârlılık durumu incelenmiş, işletmede yetiştirilen diğer ürünler dikkate alınmamıştır. Araştırmada keten yetiştiriciliğinin ekonomik olarak kârlılığının belirlenmesi amacıyla keten yetiştiriciliği için girdi kullanım miktarları ve toplam üretim maliyetleri tahmin edilmiştir.

Liflik keten üretim dönemi masrafları değişken ve sabit masraflar olarak ikiye ayrılmıştır. Sabit masraflar üretim miktarına bağlı olmayan masraflar iken, değişken masraflar üretim miktarına bağlı olarak değişen masraflardır (Erkuş ve ark., 1995). Değişken masraflar; derin sürüm, ikileme, tırmık, tohum fide bedeli, ekim, çapalama, ot alma-seyreltme, gübreleme ve işçiliği, zirai mücadele ve işçiliği, hasat, havuzlama, lif sıyırmaistifleme-taksim, taşıma, pazarlama masrafları, tamir ve bakım masrafları, döner sermaye faizinden oluşmaktadır. Döner sermaye faizi T.C. Ziraat Bankası tarafından bitkisel üretim için açılan kredi faiz oranının yarısı üzerinden hesaplanmıştır. Sabit masrafları ise; genel idare giderleri ve tarla kirası oluşturmaktadır. Üretim dönemi sabit masraf unsuru olan yönetim masrafı değişken masrafların \%3’ü olarak hesaplanmış, tarla kirası üreticilerin beyanına göre belirlenmiştir. Araştırmada, üreticilerin kendi makinelerini kullanmaları halinde, bölgedeki birim makine kiraları esas alınmıştır (Kıral ve ark., 1999).

Liflik ketenin kârlılık analizi yapılırken brüt kâr, net kâr ve nispi kâr hesaplarından faydalanılmış ve aşağıda verilen eşitlikler yardımıyla hesaplanmıştır (Eş.1, Eş.2, Eş. 3). Gayrisafi Üretim Değeri (GSÜD), ürün fiyatı ile 
dekara verim değerlerinin çarpılması sonucu elde edilmektedir (Açıl ve Demirci, 1984; Kral ve ark., 1999; Tanrıvermiş, 2000).

$$
\begin{aligned}
& \text { Brüt Kâr = GSÜD - Değişken Masraflar (DM) } \\
& \text { Net Kâr = GSÜD - Toplam Üretim Masraflarl (TM) } \\
& \text { Nispi Kâr = GSÜD / Toplam Üretim Masrafları (TM) }
\end{aligned}
$$

Keten yetiştiriciliğinin kârlılık durumu; bölgede yoğun olarak üretimi yapılan buğday üretim faaliyeti verileri ile karşılaştırılmıştır. Buğday üretim faaliyetinin gider ve gelirlerine ilişkin veriler Samsun ve Sinop illeri Tarım ve Orman İl Müdürlükleri veri tabanlarından elde edilmiştir (TOB, 2020).

\section{Araştırma Sonuçları ve Tartışma}

Araştırma bölgelerinde liflik keten üretimi esnasında farklı yöntemler uygulanmış, bu durum ketene ait masraf ve gelirlerin de farklı olmasına yol açmıştır. Bu nedenle çalışmada keten tarımından maksimum faydayı sağlayacak üretim şeklinin belirlenebilmesi için her üretim yöntemine ait kârlılık durumu ayrı ayrı incelenmiştir (Tablo 2).

Araştırma sonucunda Sinop ili Merkez ilçesinde gerçekleştirilen üretim yöntemi sonucunda liflik keten kârlılığının en yüksek olduğu bunu Samsun ili Bafra ilçesindeki uygulamaların izlediği saptanmıştır. Fakat Sinop ili Ayancık lokasyonunda liflik keten üretiminden zarar edildiği gözlenmiştir. Bunun temel nedeni Ayancık'daki deneme alanında keten üretimine ait bütün uygulamaların hiçbir mekanizasyon kullanılmadan elle gerçekleştirilmiş olmasıdır. Ayrıca deneme alanında yapılan gözlemlerde keten üretimini gerçekleştiren çiftçinin, bakım işlemlerini ile tarımsal uygulamaları doğru ve zamanında gerçekleştiremediği, bunun sonucu olarak sap $(325 \mathrm{~kg} / \mathrm{da})$ ve tohum $(16.5 \mathrm{~kg} / \mathrm{da})$ veriminin diğer lokasyonlara göre düşük olduğu belirlenmiştir. Bu durum Ayancık lokasyonunda (lokasyon 1) liflik keten üretiminden ciddi şekilde zarar edilmesiyle (-620.3 TL) sonuçlanmış, üretimin değişken masrafları (1106.6 TL) dahi karşılanamamıştır. Sinop Merkez ilçedeki Taşmanlı köyü (lokasyon 2) deneme alanında ise üretici ketenin üretim ve bakım sürecini kendisine önerildiği şekilde tam zamanında uygulamış, bunun sonucunda da dekara alınan keten sap ve tohum verimi yüksek gerçekleşmiştir. Lif ketenlerinin sap verimi ekim tarihlerine, iklim koşullarına bağlı olmak koşuluyla $200-600 \mathrm{~kg} / \mathrm{da}$, tohum verimi ise $20-60 \mathrm{~kg} / \mathrm{da}$ arasında değişmektedir (Arslanoğlu ve ark., 2017). Sapın lif oranı \%20-24 arasında değişkenlik gösterir (Turan, 2000). Araştırmada 2 numaralı lokasyonda dekara sap $(625 \mathrm{~kg} / \mathrm{da})$ ve tohum veriminin $(60 \mathrm{~kg} / \mathrm{da})$ ortalama değerlerin üst sınırında ve hatta üzerinde olduğu, 3 numaralı lokasyonda da dekara sap $(500 \mathrm{~kg} / \mathrm{da})$ ve tohum veriminin $(50 \mathrm{~kg} / \mathrm{da})$ oldukça iyi düzeyde olduğu belirlenmiştir. Bu yönüyle incelendiğinde bölgede iklim ve bakım koşullarının iyi olması durumunda liflik keten üretiminin verim seviyesinin yüksek olması beklenmektedir. Elde edilen verim değerlerimizin, Türkiye'de 2019 yılı liflik keten verim seviyesinin $(80 \mathrm{~kg} / \mathrm{da})$ (Anonim, 2020b) oldukça üzerinde olduğu dikkati çekmektedir.

Lokasyon 2'de keten lifi üretiminden dekara 832.8 TL brüt kâr elde edilirken, üretimin mekanizasyonla gerçekleştirildiği lokasyon 3 (Samsun Bafra) deneme alanında dekardan 648.2 TL brüt kâr elde edilmiştir. Sonuç olarak işletmeler bütün masraflarını karşıladıktan sonra lokasyon 2'de $715 \mathrm{TL} \mathrm{da}^{-1}$, lokasyon 3 deneme alanında ise $533 \mathrm{TL} \mathrm{da}^{-1}$ net kâr elde etmişlerdir (Tablo 2).

Üretim masrafları incelendiğinde tüm lokasyonlarda değişken masrafların payının sabit masraflara oranla çok yüksek olduğu görülmektedir. Ancak lokasyon 1'de, lokasyon 2 ve 3'e oranla değişken masrafların oranının (\%89.3) daha yüksek olduğu dikkati çekmektedir. Bu durum lokasyon 1'de (Ayancık ilçesinde) hasat-derimtoplama (233,3 TL da $\left.{ }^{-1}\right)$, havuzlama (100 TL da $\left.\mathrm{Ta}^{-1}\right)$, lif sıyırma-istifleme ve taksim işlemleri (300 TL da $\left.{ }^{-1}\right)$ tamamen el iş̧iliği ile gerçekleştirildiği için iş̧̧ilik maliyetlerinin çok yüksek olmasından kaynaklanmıştır. Nitekim lokasyon 1'de toplam değişken masrafların \%57.2'sini bahsedilen bu masraf kalemleri oluşturmuştur (Tablo 2).

Araştırma sonucunda üretim sürecinin tamamının mekanizasyonla gerçekleştirildiği lokasyon 3'de değişken masrafların (501.8 TL) diğer deneme alanlarına göre daha düşük olduğu saptanmıştır (Tablo 2). Lokasyon 2'de de çoğunlukla mekanizasyon kullanılmasına rağmen hasat-derim-toplama sürecinde el işçiliğinden faydalanılması masrafları artırmıştır. Sonuç olarak tüm lokasyonlarda keten yetiştiriciliğinin kârlılığı üzerinde en fazla hasat ve sonrası işçilik maliyetlerinin etkili olduğu saptanmıştır. Dolayısıyla hasat işlemleri ve lif elde etme süreçlerinde makinalı tarıma geçilmesi üretim masraflarını düşüreceğinden keten yetiştiriciliğini daha kârlı duruma getirebilecektir. 


\begin{tabular}{|c|c|c|c|c|c|c|c|c|c|c|c|c|c|}
\hline & $\begin{array}{l}\text { Masraf ve Kârlılık } \\
\text { Ölçümleri }\end{array}$ & 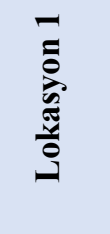 & $\underbrace{\underset{0}{\tilde{E}}}_{\tilde{E}}$ & 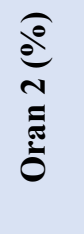 & 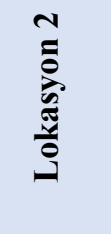 & 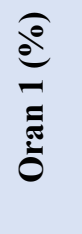 & 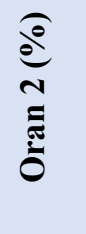 & 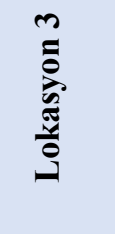 & 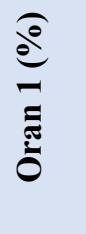 & 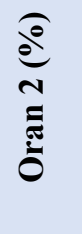 & 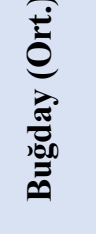 & 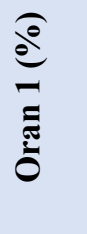 & 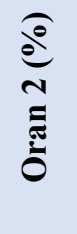 \\
\hline 1 & $\begin{array}{l}\text { Derin Sürüm } \\
\text { (Dipkazan veya Pulluk) }\end{array}$ & 75.00 & 6.78 & 6.05 & 80.50 & 13.77 & 11.46 & 34.80 & 6.94 & 5.64 & 50.00 & 12.64 & 9.85 \\
\hline 2 & $\begin{array}{l}\text { İkileme (Kazayağ1 - } \\
\text { Kültivatör) }\end{array}$ & 27.00 & 2.44 & 2.18 & 26.16 & 4.48 & 3.73 & 31.53 & 6.28 & 5.11 & 0.00 & 0.00 & 0.00 \\
\hline 3 & Tirmık & 20.62 & 1.86 & 1.66 & 16.10 & 2.75 & 2.29 & 25.14 & 5.00 & 4.07 & 20.00 & 5.06 & 3.94 \\
\hline 4 & Diskaro & 0.00 & 0.00 & 0.00 & 0.00 & 0.00 & 0.00 & 0.00 & 0.00 & 0.00 & 30.00 & 7.58 & 5.91 \\
\hline 5 & Tohum -Fide Bedeli & 64.00 & 5.78 & 5.16 & 64.00 & 10.95 & 9.11 & 64.00 & 12.76 & 10.38 & 44.00 & 11.12 & 8.67 \\
\hline 6 & Ekim & 42.00 & 3.80 & 3.39 & 20.00 & 3.42 & 2.85 & 20.49 & 4.09 & 3.32 & 20.00 & 5.06 & 3.94 \\
\hline 7 & Ot Alma -Seyreltme & 50.00 & 4.52 & 4.03 & 25.00 & 4.28 & 3.56 & 40.00 & 7.97 & 6.49 & 0.00 & 0.00 & 0.00 \\
\hline 8 & Gübreleme ve İşçiliği & 67.00 & 6.05 & 5.40 & 67.35 & 11.53 & 9.60 & 56.84 & 11.32 & 9.21 & 90.75 & 22.95 & 17.89 \\
\hline 9 & $\begin{array}{l}\text { Zirai Mücadele ve } \\
\text { İşçiliği }\end{array}$ & 20.00 & 1.81 & 1.61 & 16.85 & 2.89 & 2.41 & 20.13 & 4.01 & 3.26 & 27.00 & 6.83 & 5.32 \\
\hline 10 & $\begin{array}{l}\text { Hasat -Derim - } \\
\text { Toplama }\end{array}$ & 233.33 & 21.08 & 18.82 & 100.00 & 17.10 & 14.24 & 57.30 & 11.42 & 9.29 & 72.00 & 18.20 & 14.19 \\
\hline 11 & Havuzlama & 100.00 & 9.04 & 8.07 & 75.00 & 12.83 & 10.68 & 75.00 & 14.95 & 12.16 & 0.00 & 0.00 & 0.00 \\
\hline 12 & $\begin{array}{l}\text { Lif siyırma -İstifleme - } \\
\text { Taksim }\end{array}$ & 300.00 & 27.11 & 24.20 & 25.87 & 4.43 & 3.69 & 14.58 & 2.91 & 2.37 & 0.00 & 0.00 & 0.00 \\
\hline 13 & Nakliye. Pazarlama & 55.00 & 4.97 & 4.44 & 40.00 & 6.84 & 5.70 & 38.06 & 7.59 & 6.18 & 23.00 & 5.81 & 4.53 \\
\hline 14 & Döner Sermaye Faizi & 52.70 & 4.76 & 4.25 & 27.84 & 4.74 & 3.94 & 23.89 & 4.76 & 3.87 & 18.84 & 4.75 & 3.70 \\
\hline 15 & $\begin{array}{l}\text { Değişken Masraflar } \\
\text { Toplamı }\end{array}$ & 1106.65 & 100 & 89.26 & 584.67 & 100 & 83.27 & 501.76 & 100 & 81.34 & 395.59 & 100 & 77.95 \\
\hline 16 & Genel İdare Giderleri & 33.20 & 24.92 & 2.68 & 17.54 & 14.89 & 2.49 & 15.05 & 13.12 & 2.45 & 11.87 & 10.63 & 2.34 \\
\hline 17 & Tarla Kirası & 100.00 & 75.08 & 8.07 & 100.00 & 85.11 & 14.24 & 100.00 & 86.88 & 16.21 & 100.00 & 89.37 & 19.70 \\
\hline 18 & $\begin{array}{l}\text { Sabit Masraflar } \\
\text { Toplamı }\end{array}$ & 133.20 & 100 & 10.74 & 117.54 & 100 & 16.73 & 115.05 & 100 & 18.66 & 111.87 & 100 & 22.05 \\
\hline 19 & $\begin{array}{l}\text { Üretim Masrafları } \\
\text { Toplamı }\end{array}$ & 1239.85 & & 100 & 702.21 & & 100 & 616.82 & & 100 & 507.46 & & 100 \\
\hline 20 & $\begin{array}{l}\text { Ana Ürün (Sap) } \\
\text { Verimi }\left(\mathrm{kg} \mathrm{da}^{-1}\right)\end{array}$ & 325.00 & & & 625.00 & & & 500.00 & & & 325.00 & & \\
\hline 21 & $\begin{array}{l}\text { Ana Ürün (Sap) } \\
\text { Fiyatı }\left(\mathrm{TL} \mathrm{kg} \mathrm{kg}^{-1}\right)\end{array}$ & 1.50 & & & 1.50 & & & 1.50 & & & 1.15 & & \\
\hline 22 & $\begin{array}{l}\text { Yan Ürün (Tohum) } \\
\text { Verimi }\left(\mathrm{kg} \mathrm{da}^{-1}\right)\end{array}$ & 16.50 & & & 60.00 & & & 50.00 & & & 230.00 & & \\
\hline 23 & $\begin{array}{l}\text { Yan Ürün (Tohum) } \\
\left.\text { Fiyatı (TL kg }{ }^{-1}\right)\end{array}$ & 8.00 & & & 8.00 & & & 8.00 & & & 0.60 & & \\
\hline 24 & $\begin{array}{l}\text { Gayri Safi Üretim } \\
\left.\text { Değeri (TL } \text { da }^{-1}\right)\end{array}$ & 619.50 & & & 1417.50 & & & 1150.00 & & & 511.75 & & \\
\hline 25 & Brüt Kâr (TL da-1) & -487.15 & & & 832.83 & & & 648.24 & & & 116.16 & & \\
\hline 26 & Net Kâr (TL da-1) & -620.35 & & & 715.29 & & & 533.18 & & & 4.29 & & \\
\hline 27 & Nispi Kâr & 0.50 & & & 2.02 & & & 1.86 & & & 1.01 & & \\
\hline
\end{tabular}

* İlk 4 maddeye ait veriler, ilgili yörede buğdaya ait Tarım ve Orman İl Müdürlükleri resmi verilerinden alınmıştır. (Oran 1) Değişken ve sabit masraflar içerisindeki oranlar

(Oran 2) Toplam üretim masrafları içerisindeki oranlar

Araştırmanın yapıldığı coğrafyada keten üretimi, yaygın şekilde ekimi yapılan buğday tarımına bir alternatif olarak düşünülmektedir. Bu nedenle ketenin kârlılık analizi buğday kârlılı̆̆ ile karşılaştırılarak Tablo 2'de sunulmuştur. Tablo 2 incelendiğinde, mekanizasyonla gerçekleştirilen keten yetiştiriciliğinin ekonomik getirisinin (lokasyon 2 ve 3), bölgede yoğun olarak ekimi yapılan buğdayın ekonomik getirisinden daha fazla olduğu 
saptanmıştır. Bölgede buğday üretiminden elde edilen gelirlerin (511.8 TL) ancak masrafları (507.5 TL) karşılamaya yettiği tespit edilmiştir.

Nispi kâr, işletmeye yatırılan bir birim sermayenin üretim faaliyeti sonucunda işletmeye getirisini ifade etmektedir (Açıl ve Demirci, 1984). Sinop Merkez ilçede keten yetiştiren tarım işletmeleri keten yetiştirmek üzere yaptıkları 1 TL'lik masrafa karşılık 2.02 TL gelir elde ederken, Samsun Bafra ilçesinde 1.86 TL gelir sağlanmıştır. Mekanizasyon kullanılmasına rağmen bu lokasyonlar arasındaki farklılığın iklim, toprak farklılıkları ve kültürel işlemler nedeniyle ortaya çıkması beklenen bir durumdur. Lokasyon 2'de hasat derim toplama giderleri (100 TL $\left.\mathrm{da}^{-1}\right)$, lokasyon $3^{\prime}$ den (57.3 TL da $\left.{ }^{-1}\right)$ yüksek olmasına rağmen ikinci lokasyonda sap veriminin yüksek olması (625 $\mathrm{kg} / \mathrm{da}$ ) net kârın daha yüksek olmasına neden olmuştur $\left(715.3 \mathrm{TL} \mathrm{da}^{-1}\right)$. Bu lokasyonlarda keten yetiştiriciliğinde üretim faktörlerinin daha etkin kullanıldığı görülmektedir.

Ancak Sinop Ayancık ilçesinde ise işletmeye yatırılan 1 TL karşısında 0.50 TL gelir sağlanmakta, keten üretim maliyetlerini karşılayamadıkları için zarar etmektedirler. Diğer taraftan, keten yetiştiriciliğinde üretimi mekanizasyonla yapmak, geleneksel yöntemle (elle) yapmaya göre daha fazla kazançlı hale getirmektedir. Aydoğan ve ark., 2020 yılında Samsun ili Vezirköprü ilçesinde yürüttükleri kenevir yetiştiriciliğinin ekonomik yönünü araştırdıkları çalışmada, keneviri farklı amaçlarla yetiştiren işletmeleri incelemişler ve araştırma sonucunda keneviri lif + kıtık için ve tohum + lif + kıtık için üreten işlemelerin zarar ettiği ancak, keneviri lif + kıtık amaçlı üretirken lif sıyırma işlemini makine ile gerçekleştiren işletmelerde kâra geçildiğini belirlemişlerdir. Ürünü tohum+soyulmamış sap ve yalnızca soyulmamış sap şeklinde üretip pazarlayan işletmelerde ise kârlılığın daha yüksek olduğunu tespit etmişlerdir.

Araştırma sonucunda buğday üretim verileri incelendiğinde, yatırılan 1TL'ye karşıllı yine 1.01 TL elde edilmektedir. Araştırma sonucunda bölgede dekara buğday verimi ortalama $325 \mathrm{~kg}$ ve sap verimi $230 \mathrm{~kg}$ olup, buğdaydan elde edilen gelirlerin toplam masraflarını ancak karş̧layabildiği saptanmıştır. Erbaş (2020), Yozgat iklim koşullarında kışlık buğday üretimde nispi kârı 1.10 olarak bulmuş, üreticilerin buğday tarımından pozitif brüt ve net kâr elde ettiğini, ancak bunun yeterli olmadığını belirtmiştir. Karadaş (2016) ise Ağrı koşullarında, buğday üretiminden zarar edildiğini, üreticilerin ortalama $-0.03 \mathrm{TL} \mathrm{da}^{-1}$ brüt kâr ve $-26.68 \mathrm{TL} \mathrm{da}^{-1}$ net kâr elde ettiğini, Birinci ve Küçük'de (2011), Erzurum koşullarında buğday üretim maliyetlerinin yüksekliği nedeniyle, buğday üretimden zarar edildiğini bildirmişlerdir.

Buğday üretimi bu boyutuyla uzun dönemde ekonomik olarak sürdürülebilir değildir. Ancak münavebe, hayvan yemi ve aile ihtiyacını karşılamak amacıyla buğday ekimi gerçekleştirilmeye devam etse de, ekonomik olarak keten gibi kârlılı̆̆ yüksek ürünlere yönelinmesinde veya ekim nöbetine alınmasında yarar görülmektedir. Ekim nöbeti, sürdürülebilir tarım açısından, tarımsal girdileri azaltan, çevreye dost ve herbisit kalıntısına sebep olmayan yabancı ot mücadelesinde en başarılı yöntemlerin başında gelmektedir. Ekim nöbeti kültür bitkilerinin yetiştiriciliğinde ekim nöbeti yabancı ot popülasyonunun ve hastalık-zararlı etmenlerinin azaltılabileceği, bu sayede kültür bitkilerinde verimin yükseltilebileceği bildirilmektedir (Kara ve ark., 2011; Torun ve Uygur, 2019).

Yapılan çalışmalar Arpa + Yonca + Keten + Nadas ekim nöbeti sisteminin, Matricaria inodora L., Poa annua L., Raphanus raphanistrum L., Spergula vulgaris L., Viola arvensis L. yabancı otlarının gelişimini olumsuz etkilediğini göstermiştir (Rahnavard ve ark., 2009). Yağlık keten yetiştiriciliğinde farklı ekim nöbeti sistemlerinin araştırıldığı bir başka çalışmada (Zhao ve ark., 2020a), keten-keten-keten şeklinde üst üste keten ekimi yapılan alanlara göre, (patates-keten-keten), (buğday-patates-keten), (keten-patates-keten), (patates-buğday-keten) ve (keten-buğday-keten) uygulamaları ketenin büyümesi, yaprak alanını, kuru madde birikimini, tohum nitrojen birikimini, su ve kullanılan azotun verimliliğini artırmıştır. Rotasyon sistemlerinde keten tohumu verimleri, sürekli keten ekim sisteminden \%22.23 ila \%44.11 daha yüksek bulunmuş, Buğday ve patates anızlarında yetiştirilen ketenler daha fazla dal (\%14.24 ve \%6.97), kapsül (\%26.35 ve \%28.79) ve kuru madde (\%41.98 ve \%25.47) oluşturmuştur. Araştırıcılar ekim nöbeti uygulaması ile tohum verimi, kuru madde miktarı ve verim bileşenlerinin daha yüksek bulunduğunu, aynı zamanda, su ve gübre verimliliğini artırdığını belirlemişlerdir.

Karadeniz Bölgesinde buğday tarımı, kışlık olarak ekilebilecek bitki türünün sınırlı olması nedeniyle (buğday, arpa, yulaf, fiğ) genellikle buğday üzerine buğday tarımı şeklinde yapılmaktadır. Oysa ekim nöbeti sisteminin başarısı için farklı kök sistemine sahip bitkilerin birbiri ardına ekilmesi gerekir. Böylece, hem bitkisel ürün miktarı, hem toprak verimliliği (Chacko ve ark., 2019; Wei ve ark., 2020) hem de su tutma kapasitesini (Zhao ve ark., 2020b) artırmak mümkün olur. Yapılan çalışmalar buğday-buğday şeklinde yapılan ekimlerde buğdayın tane 
verimi ve kalite kriterlerinde düşüşler olduğunu göstermiştir (Chaieb ve ark., 2020). Keten, yonca, mısır, çavdar, korunga şekerpancarı kök nematodu ile mücadelede etkili ön bitki olmaları nedeniyle ekim nöbetine alınmaları önemli katkı sağlamaktadır (Kara ve ark., 2011). Bu nedenle buğdaydan sona tekrar buğday ekilerek yapılan üretim sisteminin uygulandığı üretim alanlarında keten buğday ekim nöbeti sisteminin uygulanması ürün ve toprak verimliliğini artırmak açısından yararlı olacaktır.

Keten bitkisi, zayıf kök sistemi ve yaprak alanının azlığı nedeniyle yabancı otlarla rekabeti zayıftır (Carlson, 2008). Bu nedenle genel olarak keten tarımı yapılan ve ekim nöbeti uygulanmayan alanlarda yabancı ot görülmekte (Özcan ve ark., 2014), mücadele edilmemesi halinde liflik veya tohum amaçlı keten yetiştiriciliğinde fark etmeksizin \%22-31 oranında verim düşüşüne neden olmaktadır (Gruzdeviene ve Jankauskiene, 2011; Carlson, 2008).

\section{Sonuç}

Orta Karadeniz Bölgesi'nde seçilen kırsal deneme alanlarında liflik ketenin üretim maliyetlerini ve kârlılığını belirlemek, ketenin buğdaya alternatif olup olamayacağını saptamak amacıyla yapılan bu çalışmada şu sonuçlar elde edilmiştir;

- Sinop ili Ayancık ilçesi Söküçayırı Köyü (Lokasyon 1) deneme alanında tüm işçiliğin elle yapılması, bakım işlemlerinin aksatılması nedeniyle üretici liflik keten üretiminden kâr elde edememiştir.

- Sinop ili Merkez ilçe Taşmanlı köyü ve Samsun ili Bafra ilçesi Elifli köyünde (Lokasyon 2 ve 3) iklim ve toprak koşullarının da etkisinde olmak kaydıyla, mekanizasyonun kullanılması işletmelerin kârlılığını artırmıştır.

- Sinop ili Merkez ilçe Taşmanlı köyünde (Lokasyon 2) ise sadece hasat ve ekim işlemlerinin makine ile yapılması, tüm kültürel ve bakım işlemlerinin zamanında tamamlanması sonucunda, üreticinin masraflarının tamamını karşıladıktan sonra dekara oldukça tatminkar bir kâr elde ettiği belirlenmiştir.

Araştırmada, liflik keten yetiştiriciliğinde yüksek kârlılık için tüm işlemlerin mekanizasyonla yapılmasının yanı sıra, doğru ve zamanında yapılan bakım ve kültürel işlemlerin de çok önemli olduğu belirlenmiştir. Buna göre liflik keten üretimi için üreticilerin değişken masraflar içerisindeki iş gücü maliyetleri ile hasat-derim-toplama, havuzlama, lif sıyırma, istifleme ve taksim işlemlerinde mutlaka mekanizasyona yer verilmesinin maliyetleri önemli derecede düşüreceği, bölge koşullarında buğdaya göre 2 kat fazla nispi kâr elde edeceği sonucuna varılmıştır. Bununla birlikte bölgede buğday üretim alanlarında buğdaydan elde edilen gelirlerin toplam masraflarını ancak karşılayabildiği, fakat buğdayın aile ihtiyacını karşılamak üzere tarımsal üretimde mutlak yer alması gerektiği dikkate alındığında, kışlık ekilen liflik ketenin Orta Karadeniz Bölgesi ve benzeri iklim koşullarında buğday ile ekim nöbetine alınması önerilmektedir. Böylelikle çiftçi ailesi temel ihtiyaçlarını karşıladıktan sonra, aynı alandan gelir getirici yeni bir ürünü üreterek gelirini artırma şansı yakalayacaktır.

Türkiye'de tekstil sektörünün ihtiyaç duyduğu pamuk dışı hammaddenin ülke kaynaklarından sağlanabilmesi olanağını artırmak amacıyla, iklim koşullarının elverişli olduğu bölgelerde gelir getirici bir ürün olarak liflik keten yetiştiriciliği teşvik edilebilir. Her ne kadar sentetik lifler daha ucuz ve kolay işlenebilir olsa da son yıllarda talebi giderek artan doğal, organik ürünlerin hammadde ihtiyacını karşılamak amacıyla da yetiştirilmesi önerilmektedir. 


\section{Kaynakça}

Açıl, A.F., Demirci, R. (1984). Tarım Ekonomisi Dersleri. Ankara Üniversitesi Ziraat Fakültesi Yayınları No. 880, Ankara.

Akin, D. E. (2000). Flax fiber. Kirk-Othmer Encyclopedia of Chemical Technology.

Anonim (2018). International Trade Centre (ITC), www.trademap.org

Anonim (2020). http://www.lifmekanizasyon.com/keten.html, (Erişim Tarihi: 23.12.2020)

Anonim (2020a). Food and Agriculture Organization (FAO), www.fao.org, (Erişim Tarihi: 28.11.2020)

Anonim (2020b). Türkiye İstatistik Kurumu (TÜİK), www.tuik.gov.tr, (Erişim Tarihi: 02.12.2020)

Arslan, O., Kahrıman, F., Topçu Bayram, Ö., Turhan, H. (2011). Çanakkale Koşullarında Yetiştirilen Keten Genotiplerinin Tohum Verimi ve Bazı Kalite Özelliklerinin İncelenmesi. Tekirdağ Ziraat Fakültesi Dergisi /Journal of Tekirdag Agricultural Faculty, 8, Sayı 3, Sayfa 1-7.

Arslanoğlu, Ş.F., Aytaç, S., Ayan, A. K. (2017). Keten. Karadeniz'in Lif Bitkileri Çalıştayı Keten-Kenevir-Isırgan, 5-6 Mayıs, Samsun. Sayfa 51-62. Basım tarihi 19.12.2017. Uğur Ofset, Samsun, ISBN:9786052319017.

Aydoğan, M., Terzi, Y., Gizlenci, Ş., Acar, M., Esen, A., Meral, H. (2020). Türkiye'de kenevir yetiştiriciliğinin ekonomik olarak yapılabilirliği: Samsun ili Vezirköprü ilçesi örneği. Anadolu Tarım Bilimleri Dergisi, 35 (1), 35-50. DOI: 10.7161/omuanajas.602585

Aytaç, S., Başbağ, S., Arslanoğlu, F., Ekinci, R., Ayan, A. K. (2020). Lif Bitkileri Üretiminde Mevcut Durum ve Gelecek. Ziraat Mühendisleri IX. Teknik Kongresi, Bildiriler Kitabı Cilt 1: 463-491. Ocak 2020. TMMOB Ziraat Mühendilseri Odası, Ankara Üniversitesi Basık Yayın Müdürlüğü, Ankara Üni. 10. Yıl Yerleşkesi Tandoğan-Ankara. ISBEN-978-605-01-1321-1.

Birinci, A., Küçük, N. (2011). Erzurum İli Tarım İşletmelerinde Buğday Üretim Maliyetinin Hesaplanması / Calculating Wheat Production Cost On The Farms In Erzurum Province. Atatürk Üniversitesi Ziraat Fakültesi Dergisi, 35 (3-4).

Bourmaud, A., Morvan, C., Baley, C. (2010). Importance of fiber preparation to optimize the surface and mechanical properties of unitary flax fiber. Industrial Crops and Products, 32(3), 662-667.

Carlson, S. L. (2008). An integrated approach to investigating the reintroduction of flax production in Iowa. Retrospective, Theses and Dissertations. 15337. https://lib.dr.iastate.edu/rtd/15337

Chacko, S., Ravichandran, C., Vairavel, S.M. (2019). Employing Measurers of Spatial Distribution of Carbon Storage in Periyar Tiger Reserve, Southern Western Ghats, India. J. Geovisualization Spat. Anal. 2019, 3, 1.

Chaieb, N., Rezguia, M., Ayedb, S., Bahria, H., M'hameda, H. C., Rezguia, M., Annabia M. (2020). Effects of tillage and crop rotation on yield and quality parameters of durum wheat in Tunisia, Journal of Animal \& Plant Sciences (J.Anim.Plant Sci. ISSN 2071-7024) Vol.44 (2): 7654-7676.

Deng, Y., Guo, Y., Wu, P., Ingarao, G. (2019). Optimal design of flax fiber reinforced polymer composite as a lightweight component for automobiles from a life cycle assessment perspective. Journal of Industrial Ecology, Vol: 23, Issue:4, pages: 986 - 997. https://doi.org/10.1111/jiec. 12836

Erbaş, N. (2020). Yozgat İli Tarım İşletmelerinde Kışlık Buğday (Triticum aestivum L.) Üretiminin Maliyet Analizi. Journal of the Institute of Science and Technology, 10 (2), 1318-1328. DOI: 10.21597/jist.607975

Erkuş, A., Bülbül, M., Kıral, T., Açıl, A. F., Demirci, R. (1995). Tarım Ekonomisi. Yayın No: 5, Ankara Üniversitesi Ziraat Fakültesi, Eğitim, Araştırma ve Geliştirme Vakfı, Ankara.

Foulk, J. A., Akin, D. E., Dodd, R. B., McAlister III, D. D. (2002). Flax fiber: potential for a new crop in the Southeast. Trends in new crops and new uses, 361 .

Foulk, J., Akin, D., Dodd, R., Ulven, C. (2011). Production of flax fibers for biocomposites. In Cellulose fibers: Bio-and nano-polymer composites (pp. 61-95). Springer, Berlin, Heidelberg.

Gruzdevienė, E., Jankauskienė Z. (2011). The Diversity Of Weeds In Organic Linseed And Flax Crop. Environment. Technology. Resources Proceedings of the 8th International Scientific and Practical Conference. Volume II., page.276-281. Rēzeknes Augstskola, Rēzekne, RA IzdevniecībaI, SBN 978-9984-44-071-2.

Heller, K., Baraniecki, P., Praczyk, M. (2014). Fibre flax cultivation in sustainable agriculture, Institute of Natural Fibres Medicinal Plants (INF\&MP), Poland, Available online 27 March 2014.

Hosseinzadeh, Y., Jalili, S., Khani, R. (2020). Investigating the effects of flax fibers application on multi-objective optimization of laminated composite plates for simultaneous cost minimization and frequency gap maximization, Journal of Building Engineering, Volume 32, 101477, ISSN 2352-7102, https://doi.org/10.1016/j.jobe.2020.101477.

Howard, J. (1941). Fiber flax grown in Oregon. Agricultural Journal, 8, 2.

Kara, B., Kara, N., Akman, Z., Balabanlı, C. (2011). Tarla Bitkilerinde Ekim Nöbetinde Ön Bitki Değeri ve Etkileri. Batı Akdeniz Tarımsal Araştırma Enstitüsü Derim Dergisi, 2011, 28(1):12-24.

Karadaş, K. (2016). Ağrı İli Tarım İşletmelerinde Buğday Üretim Maliyetlerinin Hesaplanması. Alınteri Zirai Bilimler Dergisi, 31 , $33-41$. 
Hazneci \& Arslanoğlu

Orta Karadeniz Bölgesinde Kırsal Alanlar İçin Keten Bir Şans Mı? Kârlılık Analizi ve Yapılabilirliği

Kaur, A., Singh, A., Patra, A. K., Mahajan, R. (2016). Cost-effective scouring of flax fibers using cellulase-free xylano-pectinolytic synergism from a bacterial isolate. Journal of Cleaner Production, 131, 107-111.

Keskin, G., Dönmez, D., Canik, F., Yüksel, N. Y., Sancak, A. Z. (2014). Türkiye'de Bitkisel Ürünlerde Maliyet Hesabında ve Anket Uygulamalarında Teknik Elemanların Karşılaştıkları Sorunların Belirlenmesi. Tekirdağ Ziraat Fakültesi Dergisi / Journal of Tekirdag Agricultural Faculty T. Z. F. Dergisi,11, Say1 3, Sayfa 110-118.

Kıral, T., Kasnakoğlu, H., Tatlıdil, F.F., Fidan, H., Gündoğmuş, E. (1999). Tarımsal ürünler için maliyet hesaplama metodolojisi ve veri tabanı rehberi. Proje Raporu 1999-13, Yayın No:37, Ankara.

Kiryluk, A., Kostecka, J. (2020). Pro-Environmental and Health-Promoting Grounds for Restitution of Flax (Linum usitatissimum L.) Cultivation. Journal of Ecological Engineering. Vol 21 (7): 99-107. https://doi.org/10.12911/22998993/125443.

Kuhlman, G. W., Robinson, B. B. (1938). Cost and efficiency in fiber flax production in the Willamette Valley, Oregon.

Li, M., Pu Y., Thomas, V. M., Yoo, C. G., Ozcan, S., Deng, Y., Nelson, K., Ragauskas, A.J. (2020). Recent advancements of plant-based natural fiber-reinforced composites and their applications. Composites Part B 200, 108254.

Megahed, M., Abo-bakr, R. M., Mohamed, S.A. (2020). Optimization of hybrid natural laminated composite beams for a minimum weight and cost design, Composite Structures, Volume 239,111984, ISSN 0263-8223, https://doi.org/10.1016/j.compstruct.2020.111984.

Özcan, S., Yılar, M., Kınay, A., Önen, H. (2014). The Effect of Weeds on Yield and Yield Components of Linseed (Linum usitatissimum L.). International Mesopotamia Agriculture Congress, Proceeding book 754-759. 22-25 September 2014, Diyarbakır-Türkiye.

Powers, W. L. (1936). Soil, nutrient and irrigation requirements of fiber flax.

Rada, E. L., DeLoach, D. B. (1942). The Oregon fiber-flax industry, with particular reference to marketing.

Rahnavard, A., Ashrafi, Z. Y., Alizade, H. M., Sadeghi S. (2009). Studies on the effect of fertilizer application and crop rotation on the weed infestated fields in Iran. Journal of Agricultural Technology, 5(1): 41-50.

Robinson, B. B. (1936). Fiber flax in Oregon, USA.

Savran, M., Aydin, L. (2018). Stochastic optimization of graphite-flax/epoxy hybrid laminated composite for maximum fundamental frequency and minimum cost. Engineering Structures, 174, 675-687.

Shuster, W. (1992). Ölflangen in Europa, DLG-Verglas-Gmbh, Eschborner Lands-Trabe, Germany, 122:102-107.

Shuvo, I. I. (2020). Fibre attributes and mapping the cultivar influence of different industrial cellulosic crops (cotton, hemp, flax, and canola) on textile properties. Shuvo Bioresour. Bioprocess. (2020) 7:51. https://doi.org/10.1186/s40643-020-00339-1.

Smeder, B., Liljedahl, S. (1996). Market oriented identification of important properties in developing flax fibres for technical uses, Industrial Crops and Products, Volume 5, Issue 2, Pages 149-162, ISSN 0926-6690, https://doi.org/10.1016/0926-6690(96)00009-X.

Tanrıvermiş, H. (2000). Orta Sakarya Havzası'nda domates üretiminde tarımsal ilaç kullanımının ekonomik analizi. Ankara Üniversitesi Araştırma Enstitüsü, Yayın No:42, Ankara.

TOB, 2020. Tarım Orman Bakanlığı İl Tarım Müdürlükleri Veri Tabanı. https://www.tarimorman.gov.tr/

Torun, H., Uygur, N. F. (2019). Kültür Bitkileri ile Ekim Nöbeti Uygulamalarının Yabancı Ot Yönetimine Etkisi. Turkish Journal of Weed Science 2019:22(1):127-132.

Turan, Z. M. (2000). Lif Bitkileri. Uludağ Üniversitesi Ziraat Fakültesi Ders Notları No: 83. Bursa.

Wei, C., Adamowski F. J., Liu, Y., Zhang Y., Liu C., Zhou J., Wang X., Zhang X., Cao J. (2020). A Comparative Study of Rotation Patterns on Soil Organic Carbon in China's Arid and Semi-Arid Regions. Agronomy 2020, 10, 160; doi:10.3390/agronomy10020160.

Xu, J., Gao, X., Zhang, C., Yin, S. (2017). Flax fiber-reinforced composite lattice cores: a low-cost and recyclable approach. Materials \& Design, 133, 444-454.

Yılmaz, S., Uzun, A. (2019). Keten Tarımı. Tarım ve Orman Bakanlı̆̆ı, Tarımsal Araştırmalara ve Politikalar Genel Müdürlüğü, Karadeniz Tarımsal Araştırma Enstitüsü Müdürlüğü, ISBN: 978-605-2207-25-3, Samsun.

Zhao, B., Gao, Y., Yan, B., Cui, Z., Wang, H., Zhi Cao, Z. (2020a). Varied previous crops on improving oilseed flax productivity in Semiarid Loess Plateau in China. Oil Crop Science 5 (2020) 187-193188. DOI: 10.1016/j.ocsci.2020.12.002.

Zhao, J., Yanga, Y., Zhangc, K., Jeongb, J., Zenga, Z., Zanga, H. (2020b). Does crop rotation yield more in China? A meta-analysis. Field Crops Research 245 (2020) 107659. 